\title{
ESTUDIOS
}

\section{Zamacueca a toda orquesta Música popular, espectáculo público y orden republicano en Chile (1820-1860)1.}

\author{
The Zamacueca a Tutti \\ Popular Music, Public Representation and Republican Order \\ in Chile (1820-1860)
}

\author{
por \\ Rodrigo Torres Alvarado \\ Facultad de Artes, Universidad de Chile \\ rtorres@uchile.cl
}

En el proceso que da lugar a la construcción de la república, la sociedad chilena experimenta una fuerte mutación cultural cuyo núcleo estructurador es el estatuto de la modernidad, asociado a las ideas de estado, nación y ciudadanía. En este artículo se explora esta perspectiva de transformación modernizadora desde el ámbito de la música, considerando específicamente la experiencia de la zamacueca en la primera mitad del siglo XIX. Este género de baile y música mestiza se vinculará indisolublemente con la construcción de símbolos nacionales de fuerte poder identitario; la consolidación y expansión de un sistema artístico moderno, urbano e intermedial, cuyo eje principal es el espectáculo teatral, asociado a la creación de un público masivo, y el desarrollo moderno de músicas y bailes populares locales, articulado con una incipiente industria cultural.

Palabras claves: Zamacueca, música popular, espectáculo público, orden republicano.

During the process of the creation of the Republican system in Chile, the Chilean society went through a strong cultural change. The structural core of this change is the notion of modernity, as it relates to the ideas of state, nation and citizenship. This article deals with this modernizing transformation from the standpoint of music, focusing specifically on the historical making of the zamacueca, a mestizo genre combining dance and music. The zamacueca is inextricable bound with the creation of nacional symbols closely identified with the nation, as well as with the establishment and expansion of a modern artistic system, which was both urban and intermediate. The main basis of this system is the theatrical representation associated with the creation of massive audiences, and with the modern development of local repertoires of both music and dances, linked with an incipient cultural industry.

Key words: zamacueca, popular music, public representation, republican order, nineteenth century, Chile.

1Este trabajo es fruto del proyecto FONDECYT No 1400516, Prácticas sociales de la música en Chile, 1810-1855. Estampo mi reconocimiento y agradecimiento al doctor Luis Merino Montero por su incondicional y valioso apoyo en la conclusión de este artículo.

Revista Musical Chilena, Año LXII, Santiago de Chile, Enero-Junio, 2008 N²09 


\section{INTRODUCCIÓN}

En el proceso que da lugar a la construcción de la república, la sociedad chilena experimenta una fuerte mutación cultural cuyo núcleo estructurador es el estatuto de la modernidad, asociado a las ideas de estado, nación y ciudadanía. Sin embargo, durante la primera mitad del siglo XIX persiste hegemónica una visión -fuertemente jerárquica- de la sociedad y la cultura estructurada en estamentos separados y en relación de fuerte predominio de uno respecto al otro, situación que demarca un eje de continuidad del período colonial proyectado en la sociedad decimonónica. Así, desde una visión maniquea, el estamento ilustrado representará ahora el polo civilizador y los otros grupos -mestizos, indígenas, aquí referidos genéricamente como mundo popular - el retraso y la barbarie, para usar nociones por entonces en boga 2 .

El historiador Eric Hobsbawm considera necesario para el análisis de las naciones y los fenómenos asociados con ellas tener presente su calidad de "fenómenos duales"; es decir, fenómenos "construidos esencialmente desde arriba, pero que no pueden entenderse a menos que se analicen también desde abajo, esto es, en términos de los supuestos, las esperanzas, las necesidades, los anhelos y los intereses de las personas normales y corrientes, que no son necesariamente nacionales y menos todavía nacionalistas" 3 . Frente a la evidente dificultad de conocer y documentar una tal "visión desde abajo', nos parece que en el caso chileno la zamacueca es una fuente histórica importantísima, en la medida que la vida social de este género, desde las décadas de 1820 a la de 1850, registró sensiblemente tanto la visión desde arriba como la de abajo. La presencia transversal de la zamacueca en toda la trama social - "el único punto de contacto de todas las clases de la sociedad" afirma Sarmiento en 18424 -, como elemento aglutinador y diferenciador a la vez, le otorga la calidad de potente revelador social de cambios, fricciones y conflictos centrales de aquella época de transformación modernizadora de la sociedad chilena.

En este trabajo intentamos explorar esta perspectiva considerando la antedicha mutación cultural modernizadora, desde el ámbito de experiencia histórica de la zamacueca, baile y música mestiza asociada indisolublemente a: 1) la construcción de símbolos nacionales de fuerte poder identitario; 2) la consolidación y expansión de un sistema artístico moderno, urbano e intermedial5, cuyo eje principal es el espectáculo teatral, asociado a la creación de un público masivo y 3) el desarrollo moderno de músicas y bailes populares locales, articulado con una incipiente industria cultural.

La práctica social de la zamacueca sería entonces un indicador del 'estado de modernidad' local y sus problemas. Más que solo una actividad unificadora de y entre los grupos y clases sociales, la zamacueca es también el lugar de la diferenciación, manifiesta como desconocimiento, menosprecio o fricción de estilos y comportamientos culturales, burgueses y populares, que en su espacio confluyen.

$2 \mathrm{Al}$ respecto, remito al lector especialmente al libro Facundo (1845) de Domingo Faustino Sarmiento. 3Hobsbawm 2004: 18-19.

${ }^{4}$ Cf. El Mercurio, XIV/4005 (19 febrero, 1842), p. 3.

5En este caso la intermedialidad alude a la alianza de medios donde convergen los elementos de la oralidad, los recursos y formatos del espectáculo teatral y también los de la escritura e impresión musical. Acerca de la relación entre música popular y los soportes mediales de su producción y comunicación, desde el siglo XVI en adelante, así como de la relevancia de este dominio para los estudios musicológicos, véase el interesante artículo de Nils Grosch citado en la bibliografía. 
Para abordar este amplio tema consideramos la experiencia histórica de la zamacueca en una doble serie, paralela y complementaria: la zamacueca en la chingana y la zamacueca en el teatro; poniendo énfasis en la proyección y reelaboración del género en este último espacio.

\section{LA ZAMACUECA EN LA CHINGANA}

Como aproximación a una definición de la chingana, se puede mencionar la descripción que el viajero francés Alcide D'Orbigny entrega de las chinganas ubicadas en el barrio de El Almendral en Valparaíso, en el año 18306.

"Las chinganas son casas públicas, una especie de espectáculo, donde se beben refrescos mientras se ve danzar la cachucha, el zapateo, etc., al son de la guitarra y de la voz; es un lugar de cita para todas las clases sociales, donde se incuban innumerables intrigas, pero donde el europeo se encuentra más frecuentemente fuera de lugar”.

Durante la primera mitad del siglo, la chingana, como epicentro de la fiesta popular, alcanzó un alto número, en Valparaíso, en Santiago y en otras ciudades del país. De acuerdo a El Ferrocarril, existían en Santiago más de cuarenta chinganas, que abrían los domingos y lunes de cada semana?.

La presencia de la zamacueca en las chinganas consta en diversos documentos. De estos se puede señalar lo que afirma Rafael Valdés en las Memorias publicadas por su biógrafo Miguel Luis Amunátegui Reyes8. Su referencia corresponde a Renca, está fechada el 27 de noviembre de 1831 y permite tener una idea del espectáculo en lo que entonces era un poblado campesino aledaño a Santiago.

"Haré una descripción de las tales chinganas. En una extremidad del corral o patio grande está colocado un tabladillo elevado como vara y media del terreno con su techo, algunos adornos a los lados y con las armas nacionales u otra pintura al fondo, en el que está la música compuesta de un arpa y una guitarra; en la parte del tablado que queda vacía es donde bailan dos parejas que se alternan bailando, a mi parecer, una misma cosa toda la noche, pues aunque yo me esforzaba en conocer las diferencias que me decían haber, no las alcanzaba, y para mí era lo mismo la zamacueca, que otros nombres igualmente extraños".

A esta descripción, Rafael Valdés agrega otros comentarios, que ilustran la inserción de las chinganas en el orden político conservador de esa época.

"El objeto de los paseos que se hacen a Renca en este tiempo es aparentemente el de comer fresas que hay allí con la mayor abundancia. Esto es lo que en efecto va a hacer la gente decente; pero la plebe no lleva otro que el de embriagarse y entregarse a la prostitución, en unos bailes llamados 'chinganas', de las cuales puede decirse que hay una en cada casa del pueblo. Asombrado yo de aquel desorden, pregunté por qué el Gobierno no procuraba abolir aquella costumbre, que era un germen de vicios, enfermedades, desmoralización y asesinatos; y quedé aún mas sorprendido cuando se me dijo, que lejos de eso, la Administración actual la fomentaba con el objeto, según se decía, de tener a la masa divertida y que no pensase en política; que aquellas chinganas eran una costumbre nacional pero, que en el tiempo

6D'Orbigny, II, 1839-1843: 336. Cf. Merino 1982:206.

7 El Ferrocarril, II/548 (28 septiembre, 1857).

8Pereira Salas 1941: 272-273. 
en que mandó el General [Francisco Antonio] Pinto [1826-1829],había empezado a extinguirse por los esfuerzos del gobierno lo pernicioso de ella, pero que el funesto triunfo del partido llamado estanquero [=conservador] había hecho que reviviese, por la razón ya dicha, que el primero que había establecido una chingana en esta última época era el Vicepresidente Dn Diego Portales [1831-1837] a la que asistía personalmente dos veces por semana; que el gobierno tenía en cada una espía que le daba parte de cuanto oía a los circunstantes, referente a la política".

El viajero inglés Fred Walpole, quien viajó durante cuatro años (1844-1848) en el Océano Pacífico a bordo del buque de Su Majestad, Collingswood, suministra información respecto a algunas características musicales de la zamacueca, recogidas en su paso por Valparaíso, que se mantienen vigente hasta hoy día. Estas son las siguientes: (1) el acompañamiento con arpa y guitarra; (2) el subrayar el ritmo golpeando las manos, o tamboreando sobre las cajas de las guitarras, (3) una forma de tocar la guitarra consistente en "deslizar la mano derecha a través de todas las cuerdas de la guitarra, volviéndola cada vez con un golpe en la caja"; (4) el registro agudísimo en que cantan las intérpretes, quienes "fuerzan sus gargantas hasta que casi se levantan de sus asientos para cantar más agudo"9.

\section{LA ZAMACUECA EN EL TEATRO}

La multiplicación de las chinganas y su problemática proyección como espectáculo alternativo para la sociedad civil, no tardó en entrar en conflicto con el teatro, por entonces concebido como 'escuela de costumbres' y 'difusor de las luces' desde la óptica de la cultura burguesa liberal. El año 1832 Andrés Bello publicó un artículo en el periódico El Araucano sobre el tema10. En primer lugar, denosta la actividad de las chinganas por razones de moral y orden público y por el perjuicio que ocasionaban a los trabajadores en términos tanto de ingresos como de productividad laboral. Asimismo, señala que el crecimiento de público en las chinganas ha corrido a parejas con la disminución de la asistencia de público al teatro, del que destaca su papel formador.

"No es bastante la comportación honrada del Gobierno ni la tranquilidad de que gozan los pueblos para calificar de verdaderamente feliz la situación del país. No solo son males las revoluciones y el depotismo; aun hay otros cuyos efectos perniciosos no se perciben de pronto, pero con el tiempo pueden hacerse irremediables. En medio de la paz pueden corromperse las costumbres, y arraigarse generalmente vicios más funestos que los tormentos que ocasionan los tumultos.

En medio de las ventajas que nos ha proporcionado el establecimiento del órden, se observa con desagrado una afición á ciertas diversiones que pugnan con el estado de nuestra civilización. Se ha restablecido con tal entusiasmo el gusto por las chinganas, ó mas propiamente, burdeles autorizados, que parece que se intentase reducir la capital de Chile á una grande aldea. No se crea que pretendemos criticar el justo desahogo á que naturalmente se entrega el hombre para aliviar las fatigas del trabajo; nos dirijimos contra ese frenesí que se va difundiendo á gran prisa por placeres nada decentes. Cada cual sabe la clase de espectáculos que se ofrecen al publico en esas reuniones nocturnas, en donde las sombras y la confusion de todo jénero de personas, estimulando la licencia, van poco á poco aflojando los vínculos de la moral, hasta que el habito de presenciarlos, abre la puerta á la insensibilidad y sucesivamente

9Walpole, I, 1850:105-106. Cf. Merino 1982:207.

10 El Araucano, $\mathrm{N}^{\circ} 69$ (7 enero, 1832), p. 4, cc. 1-2. 
á la corrupción. Allí los movimientos voluptuosos, las canciones lascivas y los dicharachos insolentes hieren con vehemencia los sentidos de la tierna jóven, á quien los escrupulos de sus padres ó las amonestaciones del confesor han prohibido el teatro. La mezquindad y un aparente espíritu de conciencia han hecho depreciar las representaciones dramáticas, que por defectuosas que sean, producen placeres mas nobles, que esas concurrencias fomentadoras de incentivos destructores de todo sentimiento de pudor. El jenio de la delicadeza se embota, y el espíritu de civilidad se disipa. Todas las costumbres se estragan, y la juventud mas apreciable, con semejantes lecciones, no percibe ya que sus modales tocan los límites de la grosería y el desenfreno.

Mui bueno es que el pueblo tenga sus distracciones, porque es una necesidad de la vida; pero no todas son aparentes para todas las clases de la sociedad, ni deben repetirse todos los dias, ni abandonarse á la discreción de logreros que buscan ganancias en el exceso de los placeres, y en el progreso de los estravíos. Una diversión moderada es el descanso del trabajador; mas una repeticion de actos licenciosos, como los que se han autorizado hasta ahora pocos dias en que se han intentado contenerlos con un mal dique, son el ajente de la relajacion y el fomento de los vicios mas perniciosos. El artesano consume en esas casas el producto de su taller abandonando los deberes ácia su familia; y los sirvientes domésticos, se desprenden de los cuidados de su oficio mientras malgastan el salario. Ya no es una diversión honesta la que se tiene en esos lugares, que por mas que se afane la policía en reducirlos á sus verdaderos límites, jamas lo conseguirá, porque no hai vigilancia que baste á cortar los recursos de la inmoralidad, ni tiene auxiliares dotados del celo necesario para ello. Muchas veces éstos fomentan los desórdenes que se les manda impedir, y hacen inútiles los mas esforzados empeños. Esos recintos han degenerado en escuelas de relajación general, por los mismo que concurren á ellos personas que en otros tiempos los miraban con execración. Pensábamos hacer estensivas estas observaciones hasta el estado actual de nuestro teatro, que á la verdad es mui lamentable; pero solo podemos decir, por falta de tiempo, que la poca concurrencia inutiliza los esfuerzos del empresario, y quita el estímulo á los actores, mientras vemos que las chinganas se fomentan por un concurso numeroso".

El tema lo retoma Andrés Bello tres años después en otro artículo donde destaca la importancia que en todo país culto tiene el teatro "como necesario a la civilización", y reafirma la baja de asistencia de público que se ha producido11.

"El teatro de Santiago siempre frecuentado por una numerosa concurrencia compuesta en su totalidad de lo principal de las familias, de lo más florido de la juventud y lo más hermoso del sexo, se ve hoy despoblado, aun en la representación de las mejores composiciones dramáticas".

Bello vuelve a tratar el tópico de las chinganas en relación al desarrollo del teatro, a lo que agrega la incidencia de la opinión contraria al teatro de parte de muchos miembros del clero.

"Una de las causas que pudieran distraer la concurrencia del teatro sería la existencia de otras diversiones si las hubiese. Las chinganas dicen algunos; pero ¿cuál puede ser el atractivo que ofrezcan las chinganas para la primera clase de la población de Santiago que, como ha dicho un amante del teatro, ha sostenido y hermoseado siempre con su presencia los espectáculos dramáticos? ¿Puede creerse que las familias y personas que antes veíamos en nuestro teatro se han retirado de él por frecuentar las chinganas? ¿Se ha prostituido a tal extremo el gusto de la juventud, el de las señoras y el de los hombres en general, que no asistan al teatro para buscar su diversión en esos lugares destinados a la desenvoltura de las maneras soeces de la plebe?

11El Araucano, No 249 (12 junio, 1835), p. 3. 
¿Deberemos creer que allí se entretiene la concurrencia que ha desertado del teatro? No es posible abrigar esta idea; pues ella envuelve una injuria que comprende a muchas personas recomendables por su educación, moralidad y buen gusto. La guerra que muchos individuos del clero hacen al teatro en el púlpito y confesionario es otra causa a que se atribuye la falta de concurrencia a las representaciones dramáticas".

En las décadas de 1830, 1840 y 1850 se propusieron o adoptaron medidas diversas en Chile para enfrentar el conflicto de interés entre las chinganas y el teatro. En 1833 los empresarios del teatro en Valparaíso solicitaron a la Municipalidad de Valparaíso el cierre de las chinganas los domingos, día en que funcionaba el teatro. Junto con apoyar a los empresarios, los miembros de la Municipalidad acordaron en diciembre de ese año prohibir el funcionamiento de las chinganas durante la noche de los domingos 12 .

Otra medida fue cerrar las chinganas para la Semana Santa del año 1844. No obstante, según lo señala El Progreso, el resultado fue el opuesto a lo esperado, desde el momento que la tasa de delitos no disminuyó, sino que aumentó, debido a la dificultad que se le presentó a la policía para mantener el orden13.

"La falta de sucesos notables [...] no revela [...] el sosiego y el recogimiento publico al acercarse los días mas augustos de la religión; antes al contrario, tenemos que lamentarnos de ver manar sangre de una ulcera que no es fácil de cerrar.

Uno de los medios que se emplean para inspirar sentimientos religiosos a la gente del pueblo, ha dado resultados opuestos a los que se esperaban.

Desde que se cerraron las chinganas, única diversión publica a que manifiesta apego la clase trabajadora de nuestra sociedad, la policía ha visto, con asombro, aumentarse el numero de criminales en una proporción siempre creciente.

Las chinganas son en si, verdaderas sentinas de prostitucion, pero producen el bien de reunir a la parte menos educada del pueblo, cuando busca solaz, bajo la inspección de la policía en un solo lugar. Repartidos hoy y entregados a sus orgías sin que nada les contenga, los resultados son los que estamos recogiendo.

Fomentar diversiones públicas con que poder reemplazar las chinganas, reemplazar la orgía por un pasatiempo honesto, seria servir noblemente a los intereses de la moral y de la civilización".

Situaciones como esta hicieron que las chinganas continuaran con más vigor, a pesar que un periódico como la Revista Católica, representante de la Iglesia, demandara vigorosamente en 1843 a las autoridades que las cerraran14. Esto lo demuestra la siguiente noticia publicada en El Progreso relativa a las celebraciones realizadas ese año por la victoria obtenida en Yungay por el ejército chileno, frente a las fuerzas de la confederación peruano-boliviana 15 .

"En los semblantes de todos se notaba la alegria, el entusiasmo, sin qe nada hubiese qe reprochar a los qe estaban entregados a los placeres i diversiones populares. Por la noche, ubo en la plaza principal de Yungai fuegos artificiales qe estuvieron extraordinariamente concurridos, prevaleciendo en ellos la mayor compostura i moderacion de parte del populacho. La plaza estaba vistosamente decorada e iluminada; el globo qe se elevó fue saludado por mil aplausos de los concurrentes en medio de la armonias producidas por las bandas militares de música que ejecutaban el popular imno de Yungai, el cual fue cantado, al terminar la

12Hernández 1928:74. Cf. Merino 1982:206.

13 El Progreso, II/427 (28 marzo, 1844), p. 2.

14La Revista Católica, I/17 (1 diciembre, 1843), pp. 133-135.

15El Progreso, V/1307 (22 enero, 1847). 
funcion, en la plaza i en todas las calles, por coros de ciudadanos i militares. A las once de la noche, todo estaba en el mayor silencio, sin qe aya ocurrido incidente algunos de aqellos que suelen tener lugar cuando se reune tanto número de personas del pueblo con el objeto de celebrar a su modo los aniversarios de los grandes echos nacionales.

"No qeremos dejar pasar esta ocasión para contestar el articulo qe se registra en el ultimo número de la Revista Católica a propósito de la función que acabamos de describir. Mil desórdenes temia nuestra ermana en las chinganas, y pedía a la autoridad qe las impidiese. Sin embargo, tenemos la satisfacción de anunciarle qe nada de lo qe abia previsto a sucedido, i qe mui léjos de eso, cuantos las an observado este 20 de enero, se an convencido profundamente qe el mayor mal qe podia acerse a la moralidad de nuestro pueblo bajo, sería la supresión de las chinganas, en donde el ojo de la policía puede penetrar a mansalva, i velar por el mantenimiento del órden i de la moral. Aqí está el parte pasado al señor Intendente, en el cual solo se abla de un numero de presos insignificante, lo qe prueba qe la tranquilidad i moderacion prevaleció en todos los círculos populares qe se denominan chinganas."

A pesar de ello, la postura de clausurar las chinganas continuó en el debate público. En El Copiapino se argumenta esta postura ante la necesidad de mantener el orden público en esta ciudad del norte de Chile16.

"Las chinganas deben prohibirse porque son perjudiciales y dan ocasión a escándalos y tropelías, que a todo tranco deben evitarse.

No se crea que somos de aquellos que quisieran privar a la clase pobre de sus diversiones; por el contrario, ojalá pudiéramos contribuir por nuestra parte a que aquellas fueran mayores, pues los hombres que trabajan personalmente merecen para nosotros la más alta consideración. Lo que quisiéramos es evitar los escándalos, y que los concurrentes a las chinganas, paguen demasiado caro las dos o tres horas que, por su desgracia, pasan en ellas.

Hemos observado que todas las noches de chinganas, salen treinta o cuarenta jornaleros por las calles, ebrios, dando lugar a que los agentes de policía que están a la expectativa por el aliciente de la multa, los tomen y los conduzcan al vivac como sucede todos los días. Parece que la policía al conceder licencia para establecer chinganas hubiera calculado sobre el producido de las multas. Es gracioso entrar a una de estas casas en Copiapó. En ellas se baila, se canta en un tablado, por tres o cuatro personas a lo más, que son las que forman el espectáculo, estando el resto, que nunca baja de 200 personas de espectadores, bebiendo, aplaudiendo a los que bailan y poniéndose cufifos, como vulgarmente se dice, para una hora después marchar al vivac, por el solo delito de haber bebido.

Pero no para aquí el chasco; nada será si al otro día se les pusiera en libertad; pero no es así; se les exige cuatro pesos de multa, y si no tienen con que pagarlos, se les hace trabajar en el presidio como criminales. Comprendemos bien que un hombre que ande ebrio por la calle y dando gritos o peleando debe ser arrestado; pero no comprendemos cómo la policía consienta las chinganas, cuando tiene un conocimiento exacto de que todas las noches que las hay se repiten los escándalos.

Nosotros creemos que las chinganas deben ser prohibidas; pero que a los artesanos y jornaleros no se les debe privar que hagan reuniones cuantas veces quieran para divertirse, con tal que en estas no sea alterado el orden bajo ningún pretexto".

El debate entre el teatro, como sinónimo de la ilustración, y la chingana, como sinónimo de la barbarie, continuó hasta bien avanzada la década de 1850. No obstante, la solución, de acuerdo a El Ferrocarril, no consistía en suprimir totalmente las chinganas sino en reducirlas desde el número aproximado de cuarenta que existían entonces en Santiago a dos o tres, lo que además permitiría mantener mejor el orden público 17.

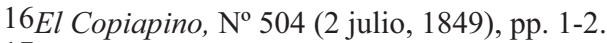

17 El Ferrocarril, No 548 (28 septiembre, 1857). 
"Entre el teatro y las chinganas hay la misma diferencia que entre la ilustración y la ignorancia, entre el buen tono y lo grotesco, entre los hermosos edificios de una población y los ranchos de sus arrabales.

Sin embargo, llega el caso en que el teatro y las chinganas no pueden existir simultáneamente. Para que el uno surja, deben arruinarse las otras, para que uno se arruine deben prosperar las otras. Bien sabida la parte principal de esta contradicción está, no en el teatro, en las chinganas, sino en la falta de público que concurre a los espectáculos. El público es siempre el mismo, y como el niño de Salomón cuando se divide ninguna de las madres goza de él. A nuestro juicio la cuestión no debe mirarse tan solo por su utilidad atendidas las contribuciones de cada una de estas diversiones; sino bajo el aspecto de la utilidad pública y de la civilización. Nuestra decisión será siempre en favor del teatro y en que se supriman absolutamente las chinganas.

La chingana corrompe el pueblo y lo precipita. La chingana invita las aspiraciones del artesano a un vaso de vino y a una borrachera. El teatro le educa, despierta en él el sentimiento de su dignidad a engrandecer sus aspiraciones.

El teatro eleva. La chingana degrada. El teatro educa al hombre de pueblo. La chingana le envilece. De todos modos y bajo cualquier aspecto que se mira la diferencia entre el teatro y la chingana, la sola existencia de aquel bastaría para que se tomasen medidas eficaces para suprimir a éstas.

No somos tan absolutos que sentemos por principio fijo la inmoralidad de las chinganas; pero condenamos el peligro de las concurrencias de tales entretenimientos por la frecuencia con que se celebran. No creemos equivocarnos al decir que pasan de cuarenta las chinganas que existen en la población, y se abren los domingos y lunes de cada semana. Y por mas decencia que en ellas se imponga, por más orden que se establezca, si es que pueda establecerse al lado de un barril de aguardiente o cuba de ponche, nunca será menos de las dos terceras partes de ellas donde se cometen excesos de todo género, las mas veces ni poder evitar un doble escándalo.

Por otra parte no deja de ser original la justicia con que en un reglamento se impone prisión a los ebrios y se tolera sin embargo que haya chinganas donde todos los placeres se reducen a la ebriedad.

Dos o tres chinganas bastarían a nuestro juicio para divertir al pueblo; pues siendo fácilmente atendidas por la policía, se cometerán menos excesos y escándalos”.

Desde el teatro mismo se plantearon otras alternativas a este incordio. Una fue la de generar un teatro popular, de acuerdo a El Progreso 18:

El teatro dramático, que no ha podido encontrar prosélitos entre las clases acomodadas de la sociedad de Santiago, se encamará en las costumbres y llegará a ser una necesidad popular si la autoridad pública comprende todas las ventajas que para la civilización puede producir. Hágase que reemplace a las chinganas, fomentándolo para darle perfección y variedad; poniéndolo por su baratura y comodidad al alcance de todos, y habremos dado un gran paso hacia la mejora de las costumbres. Corregir los sentimientos, dar ideas divirtiendo, educar por medio del placer, es la obra de los teatros populares.

Pero esos espectáculos no deben entregarse a merced de especuladores sin recursos; deje la Municipalidad que la gente rica se procure entretenimientos pagándolos directamente, pero apodérese de los que sirven para el pueblo.

Así contribuirá a formar ciudadanos, en ves de corromper hombres dando amparo a las chinganas.

Empero la más creativa y duradera fue la de gradualmente ampliar y diversificar el repertorio que se presentaba en el mismo teatro, incorporando en una misma función,

18El Progreso, IX/2510 (4 febrero, 1851). 
en grados variables, a obras teatrales de carácter diverso, a danzas de carácter popular, tales como las boleras, o de Chile, tales como la zamacueca, a música vocal consistente generalmente en arias de óperas, a música instrumental tanto orquestal como de combinaciones menores y, a contar de la década de 1840, de óperas completas las que eran preeminentemente italianas. Entre otras causales, esta medida buscó muy posiblemente el aumento y la diversificación del público asistente al teatro.

Al mismo tiempo, en torno al teatro se consolidó un circuito público complejo que abarcó a las artes escénicas y la música. Fue el teatro el espacio donde tuvieron lugar renovaciones artístico-musicales relevantes en la época, como fue la introducción de la ópera y la creación de un público masivo para la música de concierto. En torno a este circuito se concentraron importantes debates de "política cultural", sobre los cambios de costumbres y valores que la "moderna" sociedad decimonónica chilena estableció en relación a la sociedad barroca colonial, tales como los ya mencionados en relación a la chingana y el teatro.

En este marco, El Araucano19 anunciaba para el teatro una "gran función extraordinaria a beneficio de la actriz Carmen Aguilar". Agregaba que "finalizará con la Zamacueca bailada al uso de Lima por el beneficiado, y la joven Pepita, su hija". Con esto, de acuerdo con Eugenio Pereira Salas, "la Cueca debutó en el tabladillo escénico"20. Posteriormente, El Araucano anunciaba para el 26 de febrero de 1835 una "Gran función a beneficio de la joven Pepita Aguilar"21. En el sainete final, la beneficiada, acompañada de su madre, ejecutaba, "el baile del Llanto al uso del Perú, y la Zamacueca a toda orquesta".

Esta situación plantea dos preguntas: (1) ¿Por qué la zamacueca se incorporó al teatro, aparte de la causal que se ha señalado de aumentar la asistencia de público?. (2) ¿Por qué este vínculo con el Perú que manifiesta el baile de la zamacueca "al uso de Lima" en la escena junto al "baile del Llanto al uso del Perú"?

Para buscar una respuesta a la primera de estas preguntas se hará una breve digresión acerca del uso y función de lo que entonces se denominaba "bailes de la tierra", entre los cuales se contaba la zamacueca, en el salón ilustrado de la primera mitad del siglo XIX. Para este propósito resultan muy útiles los escritos de viajeros europeos que pasaron por Chile o se radicaron en el país durante este período.

Una de las principales características del salón ilustrado chileno desde, al menos, la década de 1820, es la coexistencia de los bailes de origen europeo con los bailes de la tierra. En las memorias de un oficial de marina inglés, Richard Longeville Vowell, que estuvo al servicio de Chile durante los años de 1821 a 1829, esta yuxtaposición se describe con meridiana claridad en los siguientes términos 22 .

"Contradanzas y Valses se bailan sólo por las clases acomodadas, pero a veces ejecutan también las danzas de los huasos, cantando versos más cultos que los ordinarios, e inventando en ocasiones otras canciones y tonadas para los mismos pasos y figuras".

19 El Araucano, No 228 (23 enero, 1835), p.3, c.3.

20Pereira Salas 1941:275.

21 El Araucano, $\mathrm{N}^{\circ} 232$ (20 febrero, 1835), p. 4, c.3.

22Vowell 1923. Cf. Merino 1982:204. 
Otra mirada es la del científico polaco, Ignacio Domeyko, quien se radicó en Chile y llegó a ser rector de la Universidad de Chile. Refiriéndose a las tertulias en Coquimbo el año 1838, Domeyko, señala que los bailes de raigambre europea se danzaban "solo por dar gusto a los estranjeros"23. En cambio, los bailes nacionales "unidos al canto i a la poesía, acompañados de harpa o guitarra, provocan mejor la alegría i la animacion que la cuadrilla i la orquesta de nuestros salones"24.

En similar tenor rola la observación que un viajero inglés, William S. Ruschenberg, estampara también en la década de 1830. Su comentario se refiere específicamente a otro de los bailes de la tierra, el Cuando, una danza cuyo trazado musical recuerda al del minuet francés.

Durante la primera parte del siglo XIX, el Cuando tuvo una amplia dispersión geográfica en el país. Ha sido documentado en Valparaíso y Santiago en el centro del país, Concepción y Chiloé hacia el sur, y Coquimbo en el norte25. Ruschenberg explica su división en dos partes, una lenta y una rápida. La lenta se asemeja al minuet, y su texto "contiene una acusación de ingratitud, y la advertencia que a su debido tiempo la dama sentirá y llorará tanto como ha sufrido el caballero que canta". La sección rápida es danzada con "zapateado", se acompaña por el percutir del ritmo por una o dos personas. Su texto "supone una reconciliación, y en cierta medida una pregunta de cuándo será el día de la boda"26. Ruschenberg reafirma lo señalado por Domeyko, en cuanto a que bailes de la tierra tales como el Cuando, connotan la efusión de un sentimiento de animación y alegría en el salón ilustrado. En tal sentido apunta a que "si la fiesta ha estado alegre se baila el 'Cuando', una danza característica de Chile"27.

Fue este sentimiento de animación y alegría que hizo que la zamacueca se incorporara además a bailes del salón ilustrado ofrecidos de manera oficial por la más alta autoridad política del país, el Presidente de la República. Tal fue el caso del baile ofrecido en 1839 en Valparaíso por el presidente Joaquín Prieto, con alrededor de 500 invitados, en el que junto al minuet, las cuadrillas, las contradanzas y los valses, acompañados de violines y violoncellos, se bailó la zamacueca, acompañada por arpa y guitarra 28 .

Sin embargo, otras situaciones de orden general complementan la comprensión de este fenómeno. Habida conciencia del fervor popular que genera la zamacueca, y aun considerando la necesidad de control de sus manifestaciones que provocaba en el poder civil su festiva manifestación en las chinganas, se la transformó en elemento central en la construcción de símbolos nacionales aglutinantes. Así, "elevada al rango de un baile de espectáculo público" (Sarmiento 1842) o de brillante pieza instrumental, ubicada como fin de fiesta en los primeros conciertos-recitales públicos de intérpretes-compositores virtuosos [-tales como Sivori y Herz, y luego Gottschalk, Guzmán y White], la zamacueca deviene en "baile nacional", siendo el teatro el lugar principal donde este proceso ocurre y se legitima. Ya para entonces, la autoridad civil y el espacio teatral habían desplazado

23Domeyko 1902:178. Cf. Merino 1982:205.

24Domeyko 1902:180. Cf. Merino 1982:205.

25Pereira Salas 1941:259-263.

26Ruschenberg, I, 1835:177-178. Cf. Merino 1982:206-207. Un viajero alemán, Eduard Poeppig, transcribió un Cuando, recogido en 1828 en Valparaíso el que publicara en 1835 en Leipzig. Cf. Pereira Salas 1941:332.

27Ruschenberg, I, 1835:177. Cf. Merino 1982: 205.

28Hernández 1928: 96-99; Pereira Salas 1941: 277-278. 
a la Iglesia y la autoridad religiosa como lugar e institución rectora de la vida musical en el país. Y como contraparte de esta trayectoria de la zamacueca en el teatro, sus manifestaciones en el seno de la vida popular y sus desbordes festivos, permanecerán con fuerza propia pero en cauce paralelo, progresivamente segregadas del espacio público por la acción excluyente y privatizante de la elite en el poder 29 .

La segunda pregunta formulada anteriormente tiene que ver con otra manifestación de la modernidad en Chile y América, la internacionalización de la circulación de los bienes simbólicos, en este caso la zamacueca. Chile y Perú, a pesar de la guerra sostenida entre los años 1836 y 1839, mantuvieron fluido e intenso contacto durante esta época en el corredor del Océano Pacífico, que abarcó a Lima, Callao, Valparaíso y Santiago.

En tal sentido, la interpretación en los teatros de Santiago de "la Zamacueca bailada al uso de Lima", guarda relación con un artículo publicado en tres números de $E l$ Araucano, correspondientes al 12, 14 y 16 de noviembre, respectivamente. Su título es "Costumbres de Lima", proviene de la Revista que aparecía a la sazón en la capital peruana y es la traducción de un artículo sobre las costumbres limeñas, aparecido en un periódico francés. Su autor es identificado como Mr. Botmiliau, residente en Lima "al parecer" durante algún tiempo, y, según la redacción de la Revista de Lima, acreedor a toda estima y respeto por la seriedad, interés y exactitud de su escrito30.

La narración contiene una descripción de la zamacueca peruana que se bailaba el 24 de junio, día de San Juan, durante la fiesta que se realizaba en la planicie de Amancaes, ubicada en las cercanías de Lima. Según el autor, es "la mas curiosa" de las fiestas populares peruanas, "puesto que reune todo lo que buscan los limeños en sus regocijos públicos, a saber; el ruido, el movimiento i la danza al aire libre", describiendo en los siguientes términos el sitio en que se realizaba31:

"El sitio escojido para la fiesta de los Amancaes, es tambien uno de los mas pintorescos que puedan verse en toda la América. A dos o tres kilómetros de la ciudad, en una fragosidad formada por las colinas que enmarcan en cierto modo el primer escalon de las cordilleras, que estiende un cesped verduzco en medio del que brota por los meses de junio i julio, a influjos del rocío de la noche, una multitud de flores de pétalos de oro, de caliz abierto como el de la flor de lis, que se llama en el país amancaes. Se puede comparar este sitio con un inmenso cofre donde una mano jenerosa hubiera arrojado multitud de joyas".

La zamacueca desempeñaba un papel fundamental en la fiesta desde el momento en que hombres, mujeres, blancos, negros, indios, mulatos "sambos" y "cholos" se encaminaban en masa hacia la planicie 32.

"El camino estrecho i polvoroso que conduce a la llanura, se vé cubierto desde el amanecer de una multitud fogosa i alegre dividida en muchas partidas o grupos mas o ménos numerosos

${ }^{29} \mathrm{Al}$ respecto véase "Comida, música y humor. La desbordada vida popular" de Maximiliano Salinas (2005). Sobre el punto este autor sostiene que "entre 1840 y 1925, las élites administrativas locales debieron reconocer a cabalidad que no podían crear o consolidar una nación más o menos moderna -con un Estado 'en forma' oligárquica- sin poner atajo a la vitalidad popular expresada en su mundo propio de comidas, formas musicales y sentido del humor"(p. 105).

30Los números de El Araucano son XXI/1158 (12 noviembre, 1850), p.4, cc.2-4; XXI/1559 (14 noviembre, 1850), p.3, cc.3-4; XXI/1160 (16 noviembre, 1850), p.4, cc. 3-4. La identificación del autor aparece al comienzo del primero de ellos (p.4, c.2). Cf. Merino 1981: 19-21.

31 El Araucano, XXI/1159 (14 noviembre, 1850), p.4, c.1.

32El Araucano, XXI/1159 (14 noviembre, 1850), p.4, c.2. Cf. Merino 1981:20. 
de parientes o amigos. Cada partida lleva provisiones de boca i una guitarra. Cuando la partida va a pié, toma la guitarra uno de los mas alegres peregrinos, i colocándose a la cabeza de todos sus compañeros, entona, para distraer las fatigas del viaje, algunas coplas sobre el aire popular de la zambacueca, i los demas cantan en coro, a riesgo de tragar el polvo que levanta la corriente de pasajeros i de caballos".

Según el autor, la "sambacueca" es una danza, "la única popular quizas del Perú". La acompaña una "vihuela" o guitarra que rasguea un cantor con gran fuerza y admirable entusiasmo, acompañado por una caja desfondada colocada entre las rodillas de otro cantor que percute "con fuertes puñadas". De la misma manera que otros viajeros que pasaron por Perú o Chile, el contenido del texto es calificado como insignificante y hasta llega a "una libertad grosera hasta el cinismo". Ejecutan la danza un "zambo" y una "zamba" en medio de un círculo de espectadores que animan el baile con entusiastas palmoteos. Se inicia de manera lenta y un poco desganada para cobrar gradualmente mayor animación a medida que se desarrolla su coreografía, semejante, según el autor, a la persecución de la mujer por parte del hombre. El sonido de los instrumentos se vuelve atronador, hasta que el cantor que rasguea la guitarra emite un "grito salvaje de excitación i de delirio". En el frenesí, el hombre estrecha a la mujer hasta que ésta, jadeante, deja caer su pañuelo con abandono, "mostrandose vencida en la lucha". Esta "zambacueca popular", de "ardor estrepitoso" y de libertad de movimientos, contrasta con la que se bailaba también en los salones de Arequipa, Cuzco y las ciudades del interior del Perú, descrita como "una especie de pantomima decente, lijera i rápida que presta mucha gracia al cuerpo i a la flexibilidad de los movimientos" 33 .

Algunos participantes en la fiesta continuaban la celebración por la noche en chinganas de los arrabales de Lima, la que se prolongaba a menudo hasta la madrugada. La abundancia de chicha y pisco estimulaba el baile de la zamacueca "entre los negros sobre todo, con mas frenesí que nunca"34.

Esta descripción es un importante complemento a otras descripciones de la zamacueca peruana y la fiesta de Amancaes, de William S. Ruschenberg (1835)35, Max Radiguet (1856)36 y Manuel A. Fuentes (1860 y 1866)37, a la vez que reafirma la importante participación que le cupo al elemento negro en el cultivo de este baile. A pesar de su presencia en Chile, no se conocían descripciones completas de la zamacueca peruana publicadas durante el pasado siglo en nuestro país. Se conocían solamente las referencias de Ignacio Domeyko de 1838 sobre la procedencia peruana de la zamacueca 38 y la de Daniel Barros Grez hacia finales del siglo39; las breves alusiones de José Victorino Lastarria a las "zambras bulliciosas" limeñas en su carta a Bartolomé Mitre, titulada "Lima en 1850" 40 , y los dos testimonios de José Zapiola sobre los rasgos musicales de la zamacueca peruana y su llegada a Chile, que historiadores y musicólogos han citado con frecuencia.

33 El Araucano, XXI/1159 (14 noviembre, 1850), p.4, c.3.

34 El Araucano, XXI/1160 (16 noviembre, 1850), p.4, c.4.

35Ruschenberg, II, 1835:163-168.

36Radiguet 1856:130-132.

37Fuentes 1860: 272-273; Fuentes 1866: 158-159, 163-164.

38Domeyko 1902:179.

39Barros Grez 1890; reproducido en Uribe Echevarría 1960: 211.

40Lastarria 1913:328. 
Uno de estos testimonios de Zapiola -y hasta ahora pieza clave en nuestra historiografía musical para datar el momento y modo de entrada del baile a la sociedad de Santiagoes citado por Benjamín Vicuña Mackenna en "La Zamacueca y la Zanguaraña (Juicio crítico sobre esta cuestión internacional)", y dice así: "Al salir yo...en mi segundo viaje a la República Argentina [marzo de 1824], no se conocía ese baile [la zamacueca]. A mi vuelta [mayo de 1825], ya me encontré con esta novedad"41. El otro testimonio figura en los Recuerdos de treinta años (1810-1840), y agrega: "Desde entonces, hasta hace diez o doce años, Lima nos proveía de sus innumerables i variadas zamacuecas, notables o ingeniosas por su música, que inútilmente tratan de imitarse entre nosotros. La especialidad de aquella música consiste particularmente en el ritmo i colocación de los acentos, propios de ella, cuyo carácter nos es desconocido, porque no puede escribirse con las figuras comunes de la música" 42 .

En este contexto, el artículo reproducido por Bello, constituye la descripción más completa de la zamacueca peruana publicada en Chile durante el siglo XIX, la que debe obligatoriamente ser considerada en cualquier estudio sobre el tema.

Hacia fines de la década de 1830 o comienzos de la década de 1840 se establece en el teatro la zamacueca nacional. En este tránsito jugaron un papel relevante las Petorquinas 43 . Se trataba de tres hermanas, Tránsito, Tadea y Carmen, hijas de Tránsito Pinilla y Micaela Cabrera, quienes se destacaran como cultoras eximias de la zamacueca en su chingana de su localidad natal -Petorca-, y en diversas provincias hasta que, según José Zapiola, se establecieron en Santiago en 183144.

"Las Petorquinas...se estrenaron bajo los hermosos parrones de los baños de Gómez, calle de Duarte. La concurrencia de las familias más notables de Santiago era atraída no sólo por la perfección y novedad de su canto y baile, sino también por la decencia con que se expedían".

Acerca del impacto de la labor de las Petorquinas en Santiago, Zapiola declara lo siguiente 45 .

"Las famosas Petorquinas "hicieron en el arte una revolución más trascendental que la que ocasionaron en Italia los sabios emigrados de Constantinopla en el siglo XV. La capital se cubrió de chinganas, y en la Alameda, desde San Diego hasta San Lázaro, y en la calle de Duarte [actualmente calle Lord Cochrane], en sus dos primeras cuadras, era rara la casa que no tuviera ese destino".

De la chingana, una de las Petorquinas, Carmen Pinilla, pasó al teatro protagonizando un sainete titulado Baile de Tunos. Escrito por un autor local anónimo, su principal propósito era motivar el baile de la zamacueca criolla acompañada de arpa y guitarra, y se representó el 29 de noviembre de 1842 como beneficio de esta artista46. Domingo

41 El Mercurio [Valparaíso], LV/16.630 (1 agosto, 1882), p.2, c.6.

42Zapiola 1881:85-86.

43 Al respecto es importante destacar el papel desempeñado por las hermanas Pinilla y otras mujeres artistas tales como Carmen Aguilar y su hija, Mercedes Yarna, Dominga Montes de Oca, "personalidades populares que servían de simpático nexo entre 'las nefandas chinganas', los cafés y la respetabilidad del escenario del Teatro de la Universidad" (Véase Pereira Salas 1974:209).

44Zapiola 1945:82.

45Zapiola 1945:42.

46Pereira Salas 1974: 256. 
Faustino Sarmiento escribió en El Progreso una reseña de la función47.

"Pero dejemos a Adel el Segrí, que puede ser una buena pieza si quieren, vamos a lo principal que era el Baile de Tunos, obra dramática, original, anónima, y mandada a hacer ex profeso para motivar el baile de la zambacueca. ¿De dónde sacamos, decía el otro dia la Señorita Pinilla, a un amigo suyo, una petipieza francesa y traducida al castellano en que hubiera baile, para bailar mi sambacueca? -Pero en Francia no se baila sambacueca. -No le hace; se cambian los nombres y se hace como si la cosa sucediera en Chile. -Aguarde V., yo le haré una pieza al caso. Mire V. un D. Cristóval, viejo cotudo con poncho y fraque, que salga peleando con su mujer Doña Cutufina la de los títeres, porque la vieja quiere que se dé un baile: la hija que tiene sus amantes, mima al viejo y le hace consentir en el bureo. Vienen los convidados, cada uno se apodera de una muchacha y la enamora a troche moche; un viejo acomete con la sirviente, doña Cutufina disputa a su hija los cortejos, y D. Cristóval se sienta en un rincón a pitar y cabecear -Que lindo decia la Señorita Pinilla, y de ahí? -Oh! Falta lo mas gracioso todavía. Luego se trae la guitarra; baile! Que saquen a bailar a la Señorita Pinilla; que baile la sambacueca! Que baile! Que baile! Entónces sale V. a bailar y le tamboreo yo: en seguida gritan todos bravo! Bravo! Otro y otro! Entonces sale su hermana y baila otra sambacueca; se sirve ponche como se estila, y los aplausos y el entusiasmo del público no tienen entonces límites -Que lindo, si ya me parece que estoi en la Chingana, siga V. y de ahí -Entónces el público pide al autor, y que quiere V. consiento yo en salir y luego se acaba la funcion.

Nunca se vió en el teatro una composición mas inocente y mas natural; era en efecto la candidez personificada y la naturaleza sorprendida infraganti. Se bailó y hubo un pequeño inconveniente, por el cual no fue posible pedir al autor de la pieza; concluido el baile cada uno se escabulló como pudo, y la pieza concluyó silbada ¡que impertinencia! Y no obstante haberles dicho ántes que no la silbasen. Pero peor lo hacen! Que jentes!

La orquesta ejecutó la obertura de Trento, y el walts de la Reina de Francia y algunos otros de Strauss. Los palcos estaban un si es no es vacíos: la platea concurrida y la cazuela rebozando; porque la Señorita Pinilla es una reputacion verdaderamente popular."

Por su parte El Semanario de Santiago, informa que "el éxito ha correspondido á las esperanzas de la señora Pinilla: la concurrencia fue bastante numerosa pero acaso las esperanzas del público no quedaron del todo satisfechas"48. Por otra parte, del sainete se expresó en los siguientes términos:

Concluyó la funcion con El Baile de Tunos...pero es obra chilena...silencio...no se nos diga que queremos "apagar con mano ingrata las primeras chispas de esa llama que ha prendido en nuestra juventud"; no se nos dispute nuestra calidad de chilenos, lo que seria mui inoportuno sobre todo en estos dias de calificaciones. Los espectadores no tuvieron paciencia para esperar el segundo cuadro donde debia sin duda hallarse el desenlace de esta pitipieza, pues ántes de su conclusión todo se volvió chingana, tanto en las tablas como en la platea.

¿Y qué dice ahora el acreditado periódico que pidió la Zamacueca sin escatima? Dice que nunca tuvo la intencion de que se trajesen á las tablas el harpa y la guitarra; ni ménos de que resonase en ellas la voz nazal que se usa en esta especialidad de canto; no se acordó del maldito tamboreo; y quiso en fin que se bailase la Zamacueca toda entera con el mismo aparato con que se bailan las boleras.

Sesenta y cuatro músicos de viento! El Baile de los Tunos!!! ¿Cuál será la próxima novedad?

El tránsito de Carmen Pinilla de la chingana al "tabladillo escénico" y de este al teatro, encarna en el proceso más general de tránsito entre la práctica de la zamacueca en la chingana -como evento festivo para un público no masivo- a su reelaboración como

47El Progreso, I/19 (1 diciembre, 1842), pp. 1-2.

48El Semanario de Santiago, No 22 (1 diciembre, 1842), p. 184. 
baile-espectáculo para un público masivo en el teatro. Después de 1842 la zamacueca en el teatro no se insertó en una obra teatral, como en el caso de Baile de Tunos, sino que se anunciaba como el baile de cierre de un espectáculo teatral, musical, de ballet, e incluso acrobático.

Esto se puede ilustrar en los siguientes avisos, que corresponden a los años 1848 y 1859:

1) Gran función extraordinaria a beneficio de D. Mateo O'Loglhin, primer actor y director de escena de esta capital, para el 2 de marzo de 1848.

Programa:

La comedia de Scribe Un casamiento a medianoche.

Concluida ésta se bailarán por las señoritas Vallejo y Bogardus las graciosas Boleras de la Samacueca, con las que terminará la función 49 .

2) Teatro. Única, grande y extraordinaria función, para el domingo 26 de marzo de 1848, a beneficio de don Luis Raposki, polaco.

El programa son cuatro partes.

"Concluirá la función con el precioso baile de la SAMACUECA bailada por las señoritas Bogardus" 50 .

3) Gran función extraordinaria a beneficio de Enrique Lanza, martes 22 de agosto [1848]. Programa:

Primera parte

$1^{\circ}$ acto de Don Pasquale de Donizetti.

Segunda parte

$1^{\circ}$ Dueto de la ópera $\mathrm{Il}$ crociato in Ejito de Meyerbeer, cantado por Alejandro Zambaiti y el beneficiado.

$2^{\circ}$ La Cachucha, bailada por la señorita doña Josefa Vallejo.

$3^{\circ}$ Aria de Don Bartolo de la ópera El Barbero de Sevilla, cantada por el beneficiado.

Tercera parte

$2^{\circ}$ acto de Don Pasquale.

Cuarta parte

$1^{\circ}$ Aria de la ópera Il Torcuato Tasso, tocada en el trombón por Francisco Oliva.

$2^{\circ}$ Boleras de la Samacueca, bailadas por Josefa Vallejo y Don Pasquale [Enrique Lanza]51.

4) Función a beneficio de Celestine Thierry, martes 6 de diciembre [1848].

Programa:

Sinfonía.

Comedia Plan Plan.

Gran dúo brillante para piano y violín compuesto por Benedict y Beriot sobre temas de La Sonnambula de Bellini, por Alaide Pantanelli piano y Luis Remy violín.

Estreno en Santiago del ballet histórico en 2 actos y 5 cuadros Catalina o La reina de los bandidos: en el $5^{\circ}$ cuadro, El Carnaval de Venecia, las danzas son:

$1^{\circ}$ La Lituana.

$2^{\circ}$ La Máscara, gran paso a dos.

$3^{\circ}$ La brillante.

$4^{\circ}$ Las boleras de la zamacueca.

El ballet principia con la obertura de Guillermo Tell de Rossini52.

49El Progreso, $\mathrm{N}^{\mathrm{o}} 1649$ (28 febrero, 1848).

50El Progreso, VI/1669 (22 marzo, 1848). Se trata de un espectáculo de "ejercicios gimnásticos i fuerzas hercúleas" y pruebas de resistencia al fuego, presentado por una compañía polaca.

51El Progreso, VI/1798 (21 agosto, 1848).

52 El Ferrocarril, VI/1224 (5 diciembre, 1859), p. 3. 
La reseña del beneficio de Celestine Thierry publicado en El Ferrocarril permite aquilatar como la connotación de animación y alegría, propia de la zamacueca, cobraba un vigor inusitado al insertarse en un espectáculo masivo, como el teatro53.

"La función hasta allí había sido alegre, animada, pero quedaba algo que el público esperaba con impaciencia y eran las Boleras de la zamacueca en que Thierry y el señor Orozco debían regalarnos con esta hija de la patria. Las boleras principian y el entusiasmo crece, crece el ruido, crece la bulla; y el teatro convertido en algo parecido a una reunión en familia deja oír por todas partes los gritos de una alegría desesperada. La parte más democrática de la cazuela ya no lanza gritos de animación sino que truena. Orozco ha tenido también sus bravos. Tal ha sido la función: pocas veces se ha visto concurrencia mas lucida y numerosa, y en que la espontánea efusión del público haya dado pruebas mas inequívocas de las simpatías y estimación que le merece la Thierry".

La zamacueca-espectáculo, alcanza una nueva dimensión hacia finales de la década de 1840 y comienzos de la década de 1850 . Por entonces se insertó como "aire" local/nacional en presentaciones de música instrumental en el teatro, combinadas con repertorio de música vocal y con funciones de obras cómicas dramáticas, además de ópera y danza. La introducción de este tipo de evento, modalidad cara al romanticismo europeo de recitales de instrumentistas virtuosos, se debe a dos artistas extranjeros que visitaron Chile en esa época. Uno es el gran violinista italiano Camilo Sivori, quien llegó a Chile procedente de Lima en 1848. El otro es Henri Herz 54 , destacado pianista francés de origen austriaco, quien también llegó a Santiago procedente de Lima en noviembre de 1850. Ambos artistas, incorporaron la zamacueca en sus conciertos, mediante la conjunción del virtuosismo violinista o pianístico aplicados a un género con el cual el público del teatro se identificaba en profundidad.

A modo de ejemplo se puede citar in extenso el anuncio del concierto de Camilo Sivori programado para el 22 de marzo de 1848 y publicitado en El Progreso55.

Temporada Lírica. Gran función extraordinaria, martes 25 julio, Ultimo concierto y beneficio del señor Camilo Sivori.

Al llegar la época de mi vuelta a Europa y cuando me solo me quedan escasos días de permanencia en esta ilustrada y benévola capital, le ofrezco la función que he determinado para mi beneficio.

Excusado será decir que no he perdonado medio alguno que haya podido a mi juicio contribuir para hacer lucida y completa la noche de esta función. He procurado por mi parte ejecutar todas aquellas piezas que han llamado mas particularmente la atención en los conciertos pasados y he compuesto expresamente para esta ocasión el capricho burlesco sobre la popular SAMACUECA CHILENA que dedico al bello sexo de este hermoso suelo.

El concierto será dividido en tres partes del modo siguiente:

Primera parte

El primer acto de Belisario, acabando con el duo de tenor y bajo.

53El Ferrocarril, VI/1227 (8 diciembre, 1859), p. 3.

54Entre 1845-1851 Henri Herz realizó extensas giras artísticas por el territorio norteamericano y numerosos países de América Latina.

55El Progreso, VI/1669 (22 marzo, 1848). 
Segunda parte

$1^{\circ}$ Obertura a grande orquesta.

$2^{\circ}$ La plegaria de Moisés y Aria con variaciones de una forma enteramente nueva, composición de Paganini y ejecutada EN UNA SOLA CUERDA por el señor Sivori.

Nota: El entusiasmo con que esta composición ha sido recibida en su primer concierto y los deseos de muchos aficionados, le han empeñado en repetirla.

$3^{\circ}$ Cavatina de la ópera Donna Caritea de Mercadante cantada por la Srta. Pantanelli. $4^{\circ}$ Canto del Sinsonte, o sea El Carnaval de Cuba, y variaciones caprichosas y alegres con ritmo de contradanza.

Tercera parte

$1^{\circ}$ Obertura a grande orquesta.

$2^{\circ}$ Gran duo de piano y violín sobre un tema de Guillermo Tell ejecutado por la srta Alaide Pantanelli y el sr Camilo Sivori.

$3^{\circ}$ Polaca de la famosa opera I Puritani cantada por la srta Rossi.

$4^{\circ}$ El Carnaval de Chile, variaciones burlescas sobre el tema de la SAMACUECA, compuestas expresamente para mi beneficio y dedicado al ilustrado público de esta capital.

Como otra muestra se puede citar el concierto realizado el 7 de septiembre de 1848. La participación de Sivori correspondió a la función cuadragésimo primera de la temporada lírica de ese año y consistió en tres intervenciones de Sivori intercaladas entre los tres actos de la ópera Don Pasquale de Gaetano Donizetti, concluyendo la función con $E l$ Carnaval de Chile. El anuncio apareció en El Progreso56.

Función $41^{\text {a }}$, jueves 7 de septiembre de 1848, Camilo Sivori.

La causalidad y la fortuna han traído de nuevo a nuestra capital al discípulo de Paganini, a nuestro ilustre huésped el Sr. D. Camilo Sivori que ha venido por muy pocos días a visitar por segunda vez a nuestro Santiago y a decirle adiós para siempre. No se han perdonado sacrificios para determinarlo a dejarse oír de nuevo en nuestro teatro y dará en él dos funciones. La Empresa movida en esta oportunidad, como en todas, más bien por el deseo de agradar que el de su propia conveniencia, tiene la honra de anunciar a los señores abonados y a los favorecedores al Teatro de Santiago que las funciones del Sr. Sivori serán incluidas como un nuevo adorno en las mismas de la temporada lírica.

Programa

Don Pasquale.

Entre el acto 1 y 2: Primera parte de un Gran Concierto en La Mayor compuesto y ejecutado por Camilo Sivori.

Entre el acto 2 y 3: Lucia de Lammermoor, fantasía de Concierto sobre el final de esta ópera, compuesta y ejecutada por Camilo Sivori.

Después del acto 3: El Carnaval de Chile, variaciones burlescas sobre el tema de la Zamacueca, compuestas y ejecutadas por Camilo Sivori.

El efecto electrizante que produjo El Carnaval de Chile en el público que abarrotaba el teatro se percibe en el siguiente comentario aparecido en El Progreso57.

\section{¡Sivori un portento!}

"Pasemos ahora al Carnaval chileno, o variaciones burlescas sobre el tema de la Zambacueca. Aquí está lo bueno! Violín misterioso! No ha mucho que en éxtasis divinos nos había transportado a un mundo ideal y melancólico [fantasía concierto sobre el final de Lucia

56El Progreso, VI/1808 (1 septiembre, 1848).

57 El Progreso, VI/1815 (9 septiembre, 1848). 
de Lammermoor], ahora nos arrastraba al medio de la más licenciosa orgía: turbaba de tal modo nuestros sentidos que hemos visto arder treinta mil bujías, el groc francés correr en tazones, y otras muchas visiones de orgías. ¿Quién entre nosotros no bailaba la zambacueca al golpe de: ahora... ahora... ándale... ándale? Y esto que nosotros hemos nacido en tiempos anti-zambacuecos; de modo que si anoche Sivori ha hecho sonar orgías y bailar zambacuecas a nosotros, los de estos tiempos anti-zambacuecos ¿qué sería Dios mío de los que nacieron en mejores tiempos? Finalizada esta orgía, porque esto era los que nos hacía ver el violín de Sivori, siguieron las inmensas salvas de aplausos y bravos: en esta vez se hicieron sentir de una manera extraordinaria, como si todos estuviésemos embriagados con los licores de la licenciosa orgía que forjó en nuestra imaginación el violín de Sivori, misterioso violín! Hechicero Sivori! En otros tiempos habríais pasado por brujo y cargado con los tormentos de una inquisición!

Cuando Sivori toque sobre temas zamba-cuecos, conviene que no vayan mujeres al teatro, ni tampoco hombres escrupulosos porque se corrompería su conciencia pura en esos arrebatos producidos por el violín maravilloso: pero nosotros los mundanos te damos las gracias, Sivori, de estos deliciosos momentos; hasta aquí el único que nos ha dado a conocer en toda su extensión el encanto mágico de la música.

Firma: Un armonizado

\section{PERSPECTIVAS}

Hemos considerado pertinente reproducir casi íntegro, como un anexo del trabajo, el artículo “¿La Sambacueca en el Teatro!!!”, del ilustre intelectual argentino Domingo Faustino Sarmiento, escrito durante su estadía en el país y publicado en El Mercurio de Valparaíso el 19 de febrero de 184258.

Este texto tiene el vuelo característico de su pluma y de su extraordinaria capacidad de cronista, y, para el caso, es un testimonio de gran valor documental, etnográfico incluso. Sarmiento compendia magníficamente el tránsito de la popular zamacueca de las chinganas -epicentro de la cultura festiva del 'bajo pueblo'- a la zamacueca a toda orquesta en los escenarios del Teatro. Están aquí planteados los elementos y fundamentos centrales del modo de filtraje y representación de la cultura mestiza popular en la moderna sociedad burguesa liberal latinoamericana, que hace de sus bailes más populares el sustrato de simbolización de la nacionalidad, proceso incipiente por entonces y que se decantará con perfiles nítidos en torno a la conmemoración del primer centenario de la república. De los puntos que registra y desarrolla, se pueden destacar los siguientes:

(1) El impacto visceral que causaba en el público local la zamacueca al ser presentada a toda orquesta, en comparación con las danzas de origen hispanoeuropeo que también se presentaban en el teatro.

(2) La zamacueca como "el único punto de contacto de todas las clases de la sociedad, lo único que hay verdaderamente popular", desde el momento que está presente en el salón burgués, en la chingana y en el teatro.

58El Mercurio, XIV/4005 (19 febrero, 1842), pp. 2-3. Comentario al beneficio del actor argentino Máximo Jiménez en el Teatro de la Universidad en Santiago. El programa de esta función fue el siguiente: 1) "El Macías", pieza dramática de Mariano José de Larra; 2) Baile de la sambacueca, por Dominga Montes de Oca y Carmen Pinilla; 3) "El Novio en mangas de camisa", sainete en un acto. Cf. Pereira Salas 1974:221. 
(3) El potencial aglutinador/diferenciador, además de evocador del terruño, de los bailes y músicas populares durante esta época, tales como las boleras para los españoles, el minué montonero, el cielito y la media caña para los argentinos y la zamacueca para los chilenos.

(4) Las luces que proporciona sobre la mutación de los "bailes de chicoteo" o "bailes de tierra" en bailes nacionales, los que elevados "al rango de un baile de espectáculo público" en los escenarios ilustrados, se constituirán en activos factores en la construcción simbólica del orden republicano.

(5) La centralidad de la performance, de la buena performance además, para producir la buena comunicación y participación del público en los espectáculos del teatro.

Y a manera de conclusión una pregunta: ¿presencia de qué es la comprobada transversalidad de la práctica social de la zamacueca en el Chile de la primera mitad del siglo XIX?

Es sobre todo presencia de la fiesta. La zamacueca es fiesta y su práctica social contiene siempre en estado de latencia la posibilidad de transformarse en evento de carácter festivo, en momento de expansiva alegría y animación que ensambla a una comunidad. Cuando tal acontece se activan categorías como fiesta, risa y cuerpo popular, de controvertida relación con el estatuto cultural del liberalismo burgués decimonónico. Durante el siglo XIX, y pese a la permanente regulación y control oficial de este "solaz del pueblo llano", la festiva presencia de la zamacueca permaneció como fuente de experiencias comunitarias, irradiadas vitalmente en el imaginario colectivo de este lugar del planeta.

\title{
BIBLIOGRAFÍA
}

Colecciones de Diarios y Revistas

\author{
El Araucano \\ El Copiapino (Copiapó) \\ El Ferrocarril \\ El Mercurio (Valparaíso) \\ El Museo \\ El Progreso \\ El Semanario de Santiago \\ La Gaceta del Comercio \\ La Mariposa (Valparaíso) \\ La Revista Católica \\ La Semana
}




\section{REFERENCIAS}

BARRos GREZ, DANIEL

1890 "La Zamacueca", La Academia Político-Literaria (novela de costumbres políticas). Talca: Imprenta y Litografía "Los Tiempos".

D'ORBIGNY, AlCIDE 1839-1843 Voyage dans l'Amérique méridionale. Volumen II. París: P. Bertrand.

DOMEYKO, IGNACIO

1902 "Memorias inéditas", La Revista Nueva, XXVI (mayo), pp. 173-183 (aparecieron sucesivamente en éste y en otros volúmenes de la misma publicación).

Fuentes, MANuel A.

1860 Guía histórico-descriptiva administrativa, judicial y de domicilio de Lima. Lima: Librería Central.

GROSCH, NILS

2007 "Música y medios: Hacia una perspectiva nueva en la historiografía de la música", Cátedra de Artes, II/4, pp. 19-28. Santiago: Pontificia Universidad Católica de Chile.

HERNÁNDEZ C., ROBERTO

1928 Los primeros teatros de Valparaíso y el desarrollo general de nuestros espectáculos públicos. Valparaíso: Imprenta San Rafael.

HOBSBAWM, ERIC

2004 Naciones y nacionalismo desde 1780. Barcelona: Crítica.

LASTARRIA, JOSÉ VICTORINO

1913 "Lima en 1850", Obras Completas de Don J. V. Lastarria. Edición oficial. Volumen XI (Estudios Literarios, segunda serie). Santiago: Imprenta, Litografía y Encuadernación Barcelona.

MERINO, LUIS

1981 "Don Andrés Bello y la música", RMCh, XXXV/153-155 (enero-septiembre), pp. 5-51.

1982 "Música y Sociedad en el Valparaíso decimonónico", Robert Gunther (ed). Die Musikkulturen Lateinamerikas im 19. Jahrhundert [Studien zur Musikgeschichte des 19 Jahrhunderts, Band 577. Regensburg: Gustav Bosse Verlag, pp. 199-235.

Pereira Salas, Eugenio

1941 Los origenes del arte musical en Chile. Santiago: Imprenta Universitaria.

1974 Historia del teatro en Chile. Desde sus orígenes hasta la muerte de Juan Casacuberta, 1849. Santiago: Ediciones de la Universidad de Chile.

RADIGUET, MAX

1856 Souvenirs de l'Amérique espagnole: Chili-Pérou-Brésil. París: Michel Lévy Fréres.

RUSCHENBERG, WILLIAM S.

1835 Three Years in the Pacific. Londres: Richard Bentley, 2 volúmenes.

SALINAS, MAXIMILIANO

2005 "Comida, música, humor. La desbordada vida popular", Rafael Sagredo y Cristián Gazmuri (editores), Historia de la vida privada en Chile. Tomo II. El Chile moderno, de 1840 a 1925. Santiago: Taurus, pp. 85-117.

SARMiEnTO, Domingo FAUSTINO

1842 “¿La Sambacueca en el Teatro!!! Beneficio del sr. Jiménez”, El Mercurio, Valparaíso, XIV/4005 (19 febrero), pp. 2-3. 
URIBE ECHEVARRÍA, JUAN

1960 "La Zamacueca", Antología para el Sesquicentenario

(1810-1960). Santiago: Ediciones de los Anales de la Universidad de Chile.

[VOWELL, RiCHARD LONGEVILLE]

1923 Memorias de un oficial de marina inglés al servicio de Chile durante los años de 1821-1829. Traducción de José Toribio Medina. Santiago: Imprenta Universitaria.

WALPOLE, FRED

1850 Four Years in the Pacific, in her Majesty's Ship, "Collingswood”, from 1844 to 1848. Segunda edición. Londres: Richard Bentley, 2 volúmenes.

ZAPIOLA, JOSÉ

1881 Recuerdos de treinta años (1810-1840). Cuarta edición. Santiago: Imprenta Victoria.

1945 Recuerdos de treinta años. Octava edición con prólogo y notas de Eugenio Pereira Salas [Biblioteca de Escritores Chilenos, volumen V]. Santiago: Zig-Zag.

\section{ANEXO \\ ¡La Sambacueca en el Teatro!!! Beneficio del sr. Jiménez. por Domingo Faustino Sarmiento}

"Pero pasemos al baile, que es el objeto principal de nuestro artículo. Hasta ahora solo habíamos visto en la escena las graciosas boleras, la cachucha, la gavota a veces. Dos danzarinas, que sin duda no rivalizan con Miss Ester, habían arrancado aplausos al público con sus movimientos airosos, sus maniobras acompasadas; pero esta vez ha habido algo más encantador que ha electrizado, o más bien enloquecido al público. Los aplausos han tocado en el frenesí y los gritos de ¡otro! ¡otro! tenían toda la viva expresión de un deseo popular que quiere ser satisfecho a toda costa. ¿Qué nuevos atractivos tenía el baile para el público, qué nuevas habilidades venían a excitar su admiración? Una bagatela insignificante en la apariencia, pero en realidad una cosa muy grande, y que remueve profundamente los corazones. Un baile popular, comprendido de todos, que suscita simpatías, que trae recuerdos gratos, que se liga con nuestra vida y nuestras afecciones, que hace vibrar todas nuestras fibras, que llena el alma de las más dulces emociones, y nos hace sentir la nacionalidad, la patria, el pueblo, la existencia en fin. Era la Sambacueca; pero la Sambacueca que se presentaba ante sus amigos, vestida de gala como una novia feliz, ejecutada a toda orquesta, ataviada de mil adornos y acompañada y cortejada por las boleras que la precedían y seguían con sus bulliciosas sonajas y las parleras castañuelas al fin. ¡Oh! no, no se reían los extranjeros que han visto a mil chilenos con la sonrisa en los labios, palpitante el corazón, siguiendo de hito en hito cada movimiento de la graciosa danzarina, acompañarla con mil golpes acompasados remedando el tamboreo, y haciéndole hurras, con los gritos de ;leña! ¡leña! ifuego! ifuego! idale! ;dale!. No, no se burlen de sus frenéticos aplausos, de su alegría infantil. No, el que no es chileno no puede juzgar en tan grave materia, no puede comprender porque no sabe sentir, porque no es ésta la cuerda que pone en movimiento sus fibras, porque esta batería galvánica no está montada para él, y por tanto no puede electrizarlo. Observad, o sino al español que bosteza en una luneta, mientras se representa el Otelo, o la Jaira, que a dos pasos de la orquesta no ha oido ejecutar una aria del Tancredo, o una hermosa sinfonía, observadlo cuando esta comienza a preludiar el acompañamiento de las boleras. Vereislo entonces removerlo y enderezarse en su asiento, animarse sus facciones, brillar sus ojos y convertirse su habitual gravedad en festiva alegría. Vereislo volverse todo ojos, todo oidos para gustar del mas pequeño movimiento de los danzantes, seguirlos en sus graciosos jiros, inclinar su cuerpo, como si fuera a dar airoso movimiento a las castañuelas y apreciar mil bellezas que su baile favorito esconde a los ojos profanos; porque él solo tiene la clave que explica al corazón los misterios que se encierran en aquellos pasos tan lijeros para adelante, para atrás, para los costados como el voltijeo caprichoso de dos mariposas que juguetean en el aire en aquellas 
ondulaciones de los brazos que están sacudiendo las castañuelas, mil bellezas exquisitas, mil gracias encantadoras, que se derraman por todo el cuerpo del que baila, y le forman una atmósfera resplandeciente que brilla en los ojos del espectador iniciado, y que excitan en su alma el deleite y la dicha. Si entonces lo miráis mas atento, vereis en su fisonomía los caracteres de una melancolía plácida que revela lo que en su alma está pasando. El baile nacional que presencia en tierra extraña le trae a la memoria los márgenes apacibles del Manzanares, saladas majas de la Andalucía, los perfiles confusos de las montañas de la Navarra, el cielo azulado de la Extremadura, o las campiñas floridas de la Granada, su imajinación excitada por esta cuerda que ha vibrado en su corazón en los dias felices de su infancia, y susurrado sus dulces acentos, durante los plácidos momentos de su amor primero, le transporta a la querida España, se pasea en el Prado, vé las cúpulas del Escorial, entra en Madrid, pasa por la puerta del Sol, encuentra a un amigo, se detiene a mirar a una madrileña garbosa que pasa, oye las campanas, conoce el tañido de las de cada templo...jPor Dios! No lo distraigais, es el único momento de dicha inefable que experimenta desde que el puerto de Cádiz o Barcelona vió alejarse la nave que lo traía a América, de inmerecido y heredado renombre, de desengaño y desaliento para quien viene a conocerla.

Si no os basta este hecho para juzgar cuánto importa un baile nacional, acechad a los emigrados argentinos en los momentos en que reunidos bajo un techo amigo y olvidando los rigores de un destino harto severo para no haberlo sino gloriosamente merecido, ensayan rehabilitar su nacionalidad y vivir de su patria y de sus recuerdos. El minué montonero con sus graciosos alegros, despierta sus adormecidas fantasías; parece que al escuchar su alegre y animada música, salen de un letargo y se sienten llamados a la vida por la armoniosa voz de un hada amiga. La corriente de placer que estos aires nacionales levantan, los arrastra irresistiblemente a pedir la chistosa media caña, el intrincado y general cielito. ¡Oh! entonces puede estudiarse toda su nacionalidad, sus tendencias, sus bellas artes en germen, pero fecundas ya en porvenir y en desarrollo. El que pulsa las cuerdas de la tan popular guitarra se abandona a su imajinación, y mil variaciones caprichosas comentan el tema favorito, perdiéndose en mil inspiraciones felices y en repeticiones armónicas y cadenciosas; repite los versos que le han sugerido sus numerosos poetas, y mientras las parejas se enredan en el intrincado laberinto de las figuras de estos bailes, el cantor recita, por no perder momentos en que la poesía se mezcle a las melodías de la música, versitos de cuatro sílabas llenos de malicia y jovialidad.

Los bailarines remedan con el acompasado estallido de los dedos al resonar de las castañuelas, y revelan en sus movimientos expresivos y en los giros de sus brazos su origen andaluz, y las maneras chulitas de sus gauchos y compadritos. Si dejan de bailar, cuando las poco diestras compañeras se han cansado de suplicarlo, es para entonar entre todos el himno nacional, tan conocido en otro tiempo, o el guerrero que repite: ¡A la lid, a la lid argentinos! y concluir maldiciendo al tirano que los aleja de las alegres orillas del majestuoso Plata, que solo él puede correr libre allí, lejos de montañas que estrechen su ancho lecho, y dejando mecerse entre sus ondas, cual canastillos de flores, islillas que tiñen de encarnado los floridos duraznos y embalsaman naranjeros silvestres. Brindarán, al refrescar, por la patria, por la caída del tirano. Contarán las glorias de sus antepasados, y se extasiarán contemplando el porvenir que aguarda a su república, magnifico como sus ríos, inmenso como sus llanuras, cuando en medio de sus luchas sangrientas se echan las bases de su civilización original, de igualdad, de tolerancia y libertad que atraerán a su suelo feraz y a sus climas diversos, los millones de hombres que están desbordando en Europa y pidiendo a gritos una nueva patria para no entregarse en los brazos del suicidio y los delitos, adonde por fuerza quieren llevarlos la miseria y la desesperación. Todos rivalizan en expresar un concepto; la prosa jime; el verso se subleva; todos hablan; nadie se entiende; y concluyen con tomar sus sombreros sin despedirse; con la cabeza acalorada, el alma contenta, dilatado el pecho desahogado el corazón. ¿Qué majia ha obrado este súbito entusiasmo? ¿Qué tarántula los ha picado?......El cielito, la media caña.....un simple baile nacional.

Esto, pues, importa un baile de chicoteo. Todo esto dice la sambacueca; esto significa el júbilo de un pueblo entero que con las manos y los bastones ha tamboreado en coro, en masa, a pluralidad, para acompañar con sus golpes acompasados, a la bailarina que elevaba al rango de un baile de 
espectáculo público la sambacueca, nacida entre el pueblo, y elevándose con él a una categoría, a un personaje, que destierra de los bailes a la desabrida contradanza, a la ajitada balsa [vals] y a toda esa caterva de insulsas monerías sin sentido, sin placer, sin verdadero encanto, para apoderarse ella sola de la escena, reanimar los espíritus y dominarlo todo. ¿Y por qué no? ¿Quién osaría disputarle el lugar que el sufrajio universal le ha dado? ¿Quién le echaría en cara su orijen plebeyo, después que la alta aristocracia de la moda, del tono y el buen gusto la ha hecho el objeto mimado de la predilección de las bellas y el obligado fin de fiesta de toda tertulia en que no se le condene a uno a morirse de puro fastidio? ¿Por qué no había de presentarse en el teatro? ¡A fuera los estirados criticones!

La sambacueca es el solaz del pueblo llano, llano porque no tiene el triste en qué se le ataje un grano de arena. Después de las duras tareas diarias a que la necesidad lo condena, lo aguarda en la chingana con los brazos abiertos la sambacueca su amiga: la esperanza de verla lo alienta en su trabajo; y a fin de poder presentarse en la chingana con el bolsillo un poco provisto para festejarla debida y chamuscadamente es que el pobre proletario se desvive y se afana. Sino, no trabajara, ¿para qué? La sambacueca es el único punto de contacto de todas las clases de la sociedad, lo único que hay verdaderamente popular. Baila el pobre como el rico; la dama como la fregona; el roto como el caballero, con la diferencia sólo del modo; los rústicos la bailan con un poco de naturalidad, lo que llamamos a todo trapo; pero así lo hacen todo: cuando se ríen lo hacen a carcajadas, si lloran aturden, si murmuran desuellan, si se enojan matan: las jentes cultas se andan con más tiento para todo. Ved una linda y apuesta joven que se para a bailarla. Dobla graciosamente su blanco pañuelo; compónese y desarruga el vestido; echa miradas furtivas al círculo de espectadores: en un santiamén ha contado los jóvenes que van a verla bailar, y visto el lugar que ocupa el predilecto. Sus mejillas se sonrojan, la sonrisa más dulce y más venenosa de que puede disponer asoma en sus traidores y fementidos labios; principia el canto y se lanza como un cisne jugueteando en las aguas, como un esquife dorado; las gracias la acarician y mil amorcillos revolotean auyentados por las ondulaciones que el pañuelo describe; su lindo cuerpecillo va en sus graciosas vueltas y revueltas haciendo efectivo punto por punto este precioso verso popular, que es la pintura ideal de la sambacueca:

\section{La culebra en el espino Se enrosca y desparece, La mujer que engaña a un hombre Una corona merece.}

Mil aplausos la siguen hasta su asiento; ¡Otro y otra! y me paro yo. Apenas ocupo el centro de la sala cuando ya empiezo a sentir un hormigueo que me sube de los pies a la cabeza; el placer y la dicha me rebosan por todos los poros; tuerzo mi pañuelo; retoco el peinado; paseo miradas de orgullo y satisfacción por toda la asamblea; clavo los ojos en la cantora; iQué martirio! ¡se ha desafinado la prima!; cambio de postura; una pierna principia a bailar sola; la traigo arrastrando a su puesto; miro a mi compañera que ya pone, ya no pone la mano en el voluptuoso farrete; las venas se me hinchan; el corazón me late con tal fuerza que me sofoca; respiro fuego, ipor fin cantan! y todos los objetos terrenos se confunden a mi vista: me desprendo del pavimento, siento que la sangre se me va a la cabeza; no veo nada; no oigo sino una armonía lejana, lánguida como el amor feliz; me parece que vago en el espacio acompañado de una sombra celestial de mujer que revolotea en derredor mío, que aparece y desaparece a mi vista; como Sancho en clavileño, toco las estrellas, las saco de sus casillas. ¡Eh! ¡pataratas! ¡no valen un cigarro! Los estrepitosos aplausos me vuelven al mundo, a la realidad, a la vida material.... ¡Dichosos los que ganan su vida bailando la sambacueca!

¿Y el Novio en mangas de camisa? Muy agraciado; pero nunca como una sambacueca bailada en el teatro por la señorita Montes de Oca, acompañada por toda la orquesta y tamboreada por mil jóvenes entusiastas, que aplaudíamos hasta aturdir, y gritábamos a riesgo de desternillarnos. 